\title{
The Frequency of Mandibular Third Molar Impaction in Different Types of Vertical Skeletal Faces
}

\author{
Sana Viqar ${ }^{1}$ \\ Sadia Rizwan ${ }^{2}$ \\ Syed Shah Faisal ${ }^{3}$ \\ Syed Sheeraz Hussain ${ }^{4}$
}

\author{
BDS \\ BDS, FCPS \\ BDS, FCPS \\ BDS, DCPS (HCSM), MCPS, FCPS
}

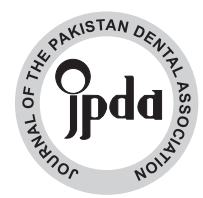

OBJECTIVE: To determine the frequency of mandibular third molar impaction in different vertical skeletal facial types. METHODOLOG: Data was collected using pre-treatment records including orthodontic files, pre-treatment lateral cephalograms and OPGs of 90 orthodontic patients. Patients from both genders were included. The age group of selected patients was 18-30 years. Vertical skeletal malocclusion was measured using facial angle and mandibular plane angle on cephalogram to group the subjects into Mesiofacial, Brachyfacial and Dolichofacial patients. Third molar eruption status was assessed using OPG. RESULTS: Results showed that erupted third molars were mostly found in brachyfacial patients. Among 32 erupted mandibular third molars, 16 belong to brachyfacial, 11 belonged to mesiofacial and 5 belonged to dolichofacial group. Complete impaction of mandibular third molar was most common among dolichofacial patients. Among 29 completely impacted mandibular third molars, 14 belong to dolichofacial, 9 belonged to mesiofacial and 6 belonged to brachyfacial group. No significant difference was found for partially impacted third molars among the three groups of facial types. There was higher prevalence of mandibular third molar impaction in females as compared to males.

CONCLUSION: Frequency of third molar impaction was found to be highest in dolichofacial patients and lowest in brachyfacial patients due to forward direction of mandibular growth contributing to greater resorption of the anterior border of ramus and the additional space required for third molar eruption.

HOW TO CITE: Viqar S, Rizwan S, Faisal SS, Hussain SS. The frequency of mandibular third molar impaction in different types of vertical skeletal faces. J Pak Dent Assoc 2021;30(2):118-123.

DOI: https://doi.org/10.25301/JPDA.302.118

Received: 20 November 2020, Accepted: 12 February 2021

\section{INTRODUCTION}

I mpacted tooth is defined as "a tooth which is completely or partially unerupted and is positioned against another tooth, bone or soft tissue so that its further eruption is unlikely, within the expected time". ${ }^{1}$ When teeth fail to develop or erupt in their correct functional location, they become impacted. ${ }^{2}$ Studies have reported third molar as one of the most commonly impacted tooth accounting for $98 \%$ of tooth impactions. ${ }^{3,4}$ Mandibular third molar has more tendency for impaction as compared to maxilla. ${ }^{5}$ It was noted that 3 to 4 years of ageis the time when crypt formation ofthird molar begins, while calcification starts at

1. Postgraduate FCPS Resident, Department of Orthodontics, Karachi Medical and Dental College, Karachi.

2. Assistant Professor, Department of Orthodontics, Dr. Ishrat-ul-Ibad Khan Institute of Oral Health Sciences, Karachi.

3. Professor, Department of Orthodontics, Karachi Medical and Dental College, Karachi.

4. Professor and Principal, Head of Department Orthodontics, Karachi Medical and Dental College, Karachi.

Corresponding author: "Dr. Sana Viqar" < sanaviqar@yahoo.com > the age of 7 to 10 years. ${ }^{6}$ Third molar eruption time varies, starting from 16 years until 18-20 years or even later in life depending on dental and bony changes among different individuals. $^{7}$

Because this molar is the last tooth in the mouth to erupt, one hypothesis has been proposed that impaction of this tooth is because of lack of space in retromolar area which occurs due to reduction in human jaw size with evolution. ${ }^{8}{ }^{8}$ Regardless of adequate growth, third molar impaction can occur if dentition does not move forward due of lack of interproximal wear (attributable to diet changes in the modern population). In a study by Gooris et al. (1990), it was noted that after second molar extraction, third molars were rarely observed impacted, suggestive of an increase in the eruption space. Likewise Kim et al. (2003) suggested that extraction of premolar as a part of orthodontic treatment resulted in decreased frequency of third molar impaction. Such studies show that third molar impaction occurs mainly due to lack of eruption space. ${ }^{10}$ 
Inadequate space at retromolar area is also associated with the direction of growth. The direction of growth of facial skeleton determines the vertical facial type. In a "mesiofacial" pattern, facial skeleton growth is forward and downward with a relative harmony between two directions. In "brachyfacial" pattern, there is anticlockwise rotation of mandible resulting in wide face and reduced anterior facial height. In "dolichofacial" pattern, clockwise rotation of mandible results in long face and increased anterior facial height. ${ }^{10}$

Broadbent believed that third molar impaction occurred when mandible failed to grow till its full potential. ${ }^{11}$ Bjork emphasized on role of direction of growth inimpaction; reduced growth with a downward direction rather than forward being associated with impaction of mandibular third molar. ${ }^{6}$ In a study by Legovic et al., no significant association was found in mandibular third molar eruption status and the type of facial growth. ${ }^{12}$ As studies show controversial results, this provides a strong rationale to conduct this research in Pakistani population, as our population differs genetically and geographically. If results of this study show dominance of mandibular third molar impactions in patients with downward growth pattern, the possible role of skeletal vertical growth in impaction of third molar could be identified and it may become possible to predict third molar impaction ahead of time in vertically growing patients. Thus, the objective of this study is to determine the frequency of mandibular third molar impaction in different vertical skeletal types of faces.

\section{METHODOLOGY}

The study was conducted at Orthodontics department, Karachi Medical and Dental College, Karachi, Pakistan. Duration of study was 6 months after getting approval from Ethical Review Comittee. Study design was cross-sectional. By using WHO sample size calculator, by taking statistics for third molar impaction as $33.33 \%^{2}$, margin of error as $10 \%$ and $95 \%$ confidence interval; the sample size was calculated to be 86. Stratified sampling was used. Sample consisted of 90 patients. Verbal informed consent was taken from the patients and all data was collected by a single researcher. The inclusion criteria was patients of age range between 18-30 years with good quality pre-treatment OPGs and lateral cephalometric x-rays available, having mesiofacial, brachyfacial and dolichofacial skeletal pattern and all permanent dentition present including third molars. The exclusion criteria was history of orthodontic treatment or orthognathic surgery, craniofacial anomalies/syndromes, any tooth anomaly of number, size, form and position and retained deciduous teeth.
The skeletal type of face was determined on lateral cephalogramby measuring facial axis angle and mandibular plane angle. Landmarks identified on the lateral cephalogram included Nasion(Na), Basion(Ba), Gnathion( $\mathrm{Gn}$ ), Porion(Po), Orbitale(Or), Menton(Me) Pterygomaxillary fissure(Ptm) and Antegonion(Ag). Facial axis was measured as the posterior angle formed by the lines Basion-Nasion and Pterygomaxillary fissure-Gnathion. Mandibular plane angle was measured as angle formed between Frankfort horizontal plane(Porion-Orbitale) and Mandibular plane (Antegonion-Menton) on lateral cephalogram. Patients were divided into three categories according to vertical facial types; - - Mesiofacial (Facial axis angle $90 \pm 3$ and mandibular plane angle 26 \pm 3 ). II - Brachyfacial (Facial axis angle $>93$ and mandibular plane angle <23). III - Dolichofacial (Facial axis angle $<87$ and mandibular plane angle $>26$ ).

Mandibular third molar impaction status was assessed on OPG x-ray. The level of impaction of third molar was categorized into three groups on basis of Pell and Gregory classification:

1. Level A defined as "the highest part of the mandibular third molar was on the same level or below the occlusal plane of the adjacent second molar". ${ }^{7}$

2. Level B defined as"the highest part of the mandibular third molar was below the occlusal plane but above the cervical line of the second molar". ${ }^{7}$

3. Level C defined as"the highest part of the mandibular third molar was beneath the cervical line of the second molar". ${ }^{7}$

Three groups were established on the basis of third molar eruption status; A - Erupted third molar (Level A of $P \& G$ ), B - Partially impacted third molar (Level B of $\mathrm{P} \& \mathrm{G}), \mathrm{C}$ - Complete impaction (Level C of $\mathrm{P} \& \mathrm{G}$ ).

\section{DATA ANALYSIS}

Analysis of collected data was done using SPSS version 23.0. The subjects were divided into three groups and their presence measured in frequency and percentage. The frequency of third molar impaction in different vertical skeletal types of faces was measured as percentage. The subjects were then also categorized according to gender and frequency of third molar impaction was found for males and females.

\section{RESULTS}

A total of 90 patients were included in this study who were divided into three groups depending on skeletal vertical facial type - 30 mesiofacial, 30 brachyfacial, 30 dolichofacial. Each facial group comprised of $33.3 \%$ of total subjects in 
this study. All patients were evaluated radiographically. The distribution of mandibular third molar impaction status in different vertical facial types is shown in Table 1.

Table 1: Distribution of third molar impaction in different facial types

\begin{tabular}{|c|c|c|c|c|c|c|}
\hline & & & & Third molar & & \\
\hline & & & Erupted & $\begin{array}{l}\text { Partial } \\
\text { impaction }\end{array}$ & $\begin{array}{l}\text { Complete } \\
\text { impaction }\end{array}$ & Total \\
\hline Facial & Mesiofacial & Count & 11 & 10 & 9 & 30 \\
\hline type & & $\%$ within Facial type & $36.7 \%$ & $33.3 \%$ & $30.0 \%$ & $100.0 \%$ \\
\hline & Brachyfacial & Count & 16 & 8 & 6 & 30 \\
\hline & & $\%$ within Facial type & $53.3 \%$ & $26.7 \%$ & $20.0 \%$ & $100.0 \%$ \\
\hline & Dolichofacial & Count & 5 & 11 & 14 & 30 \\
\hline & & $\%$ within Facial type & $16.7 \%$ & $36.7 \%$ & $46.7 \%$ & $100.0 \%$ \\
\hline Total & & Count & 32 & 29 & 29 & 90 \\
\hline & & $\%$ within Facial type & $35.6 \%$ & $32.2 \%$ & $32.2 \%$ & $100.0 \%$ \\
\hline
\end{tabular}

Results showed that complete impaction of mandibular third molar was most common among dolichofacial patients. Among 29 completely impacted mandibular third molars, 14 belong to dolichofacial, 9 belonged to mesiofacial and 6 belonged to brachyfacial group. Erupted third molars were mostly found in brachyfacial patients. Among 32 erupted mandibular third molars, 16 belong to brachyfacial, 11 belonged to mesiofacial and 5 belonged to dolichofacial group. There was no significant difference for partially impacted third molars among the 3 groups of facial types. Results show significant differences in frequency of third molar impaction among male and female patients, with their increased prevalence found in females as compared to males. The distribution of mandibular third molar impaction in different genders is shown in Table 2.

Table 2: Distribution of third molar impaction among different genders

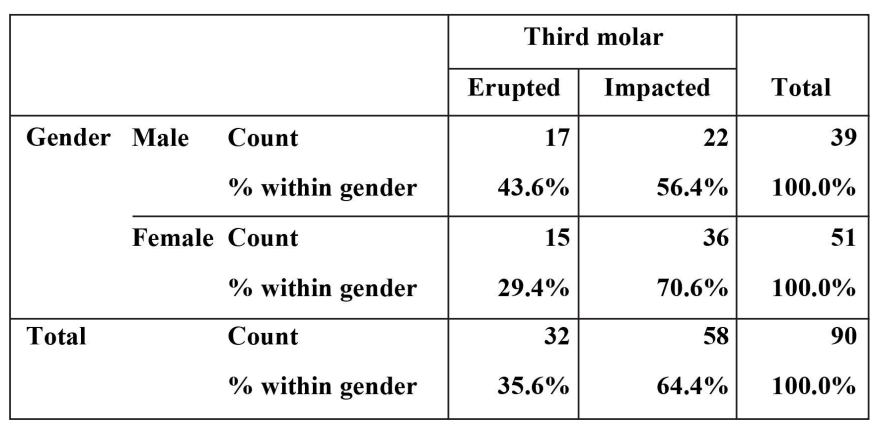

\section{DISCUSSION}

Consideration of mandibular third molar status is important from orthodontic viewpoint as these teeth are considered to be responsible for crowding of lower anterior teeth, relapse in the lower anterior crowding after orthodontic treatment, interfering with uprighting of first and second molars, distalization of molars, caries, and pericoronitis. ${ }^{2}$ The complications of third molar impaction can be prevented with timely proper orthodontic treatment. ${ }^{13,14}$

In this study, the frequency of mandibular third molar impaction was found to be $64.4 \%$. This is in consistence with the findings of Nanda and Sandhu and Kaur who noted $40 \%-68.9 \%$ of third molar impaction in South Indian population. ${ }^{15,16}$ However, results of this study differed from those observed by Obiechina et al., who found prevalence of third molar impaction to be $72.09 \%$ of the Nigerian population, and also Grover and Lorton who observed $96.5 \%$ of the third molar impaction. ${ }^{17,18}$ In addition, the frequency found in this study was significantly more than that of Scherstén et al. who observed 33\%, Hattab et al. who observed $28.2 \%$ and Ma'aita who found $40.5 \%$ of third molar impaction. ${ }^{19-21}$ Moreover, in this study the frequency of mandibular third molar impaction in males was found to be $56.4 \%$ and $70.6 \%$ in females. This is similar to findings of the majorityof authors that prevalence of third molar impaction is greater in females as compared to males..$^{10}$ The similar rates of impaction among genders were found in the study by Dachi and Howell. ${ }^{22}$

In this study the sample was categorized according to the vertical skeletal malocclusion of patient. The mandibular plane angle indicates growth direction of mandible, with high values representing dolichofacial subjects and low values representing brachyfacial ones. Facial axis, whose value is determined by the shape and position of the mandible, indicates growth direction of the chin and is not susceptible to change by age. Thus, values above $90^{\circ}$ point to forward growth (brachyfacial pattern). ${ }^{23}$ Therefore, mandibular rotation which ultimately determines the pattern of facial growthis a significant factor affecting the retromolar space. $^{7}$

Lack of retromolar space between distal of second molar and the ascending ramus mostly affects mandibular third molar causing failure of its eruption. Bjork et al. noted that patients in whom mandibular third molar was impacted, 90\% were found to have decreased space in the retromolar area. ${ }^{24}$ Mandibular growth direction plays a significant role in third molar eruption. Third molar eruption can be impeded if the anterior aspect of mandibular ramus has reduced remodeling resorption. In patients with anterior growth rotation, compensation for this reduced resorption occurs by more forward eruption of third molars during functional phase. $^{7}$

It was also demonstrated that three skeletal factors contribute to this diminished space; 1) Short mandibular length 2) Vertical direction of condylar growth 3) Backward directed eruption of the dentition. ${ }^{10}$ The most important factor was the vertically directed condyle growth, found 
predominantly in dolichofacial subjects. ${ }^{10}$ Capelli claims that third molars are found to become impacted more frequently in mandibles with a vertical growth pattern. ${ }^{25} \mathrm{~A}$ long ramus with short mandibular length are thought to be indicative of the impaction of mandibular third molar. ${ }^{26}$ Results of this study showed that majority (48.3\%) of all completely impacted teeth belonged to patients with dolichofacial pattern.

The short mandibular length which is considered second most important factor, predisposed to impaction of third molar. Conversely, according to Kaplan and Dierkes, there was no significant difference in mandibular lengthsof patients with erupted and impacted third molars. ${ }^{24}$ Eroz et al. and Capelli found in their studies that patients with dolichofacial facial growth pattern had shorter mandibular lengths, consistently supporting the hypothesisof greater chances of third molar impaction in patients with dolichofacial pattern $(26,27)$. These findings are in consistence with results of this study which showed that among all erupted third molars, $50 \%$ belonged to brachyfacial group, $34.4 \%$ belonged to mesiofacial group and $15.6 \%$ belonged to dolichofacial group.

Nanda et al, noted that growth period varied from one facial form to another. It was shown that compared to dolichofacial patients, brachyfacial patients had a longer period of facial growth. ${ }^{28}$ This extended growth period accounts for greater resorption of the anterior border of ramus resulting in an increase in retromolar space. According to Breik et al., the prevalence of mandibular third molar impaction was almost two times less in short face patients as compared to long face patients. ${ }^{27}$ These finding are in consistence with the results of our study. However, in a study by Sogra et al. 2014, no statistical significant difference was found among the frequency of mandibular third molar impaction in different facial growth patterns. ${ }^{7}$

This study showed no significant difference in impaction and eruption rates of third molar in mesiofacial group. This could be due to limitations in the study including number of subjects and the sample type. Patients coming for orthodontic treatment usually present with dentoskeletal malocclusions and thus, they have higher chances of impaction of mandibular third molar. ${ }^{10}$ Another limitation in this study related to sample could be the age limit. The age range of patients involved in this was 18 to 30 years. Growth of mandible is normally completed by $16-17$ years and development of third molar is usually at its final stage at 18 years. Recent literature has shown that vertically positioned third molars may undergo progressive uprighting up to the age of 25 resulting in their complete eruption in the oral cavity. ${ }^{4}$ A tooth impacted at 18 years of age has approximately 30 to $50 \%$ chance of complete eruption, except horizontal impactions. ${ }^{29}$ In a study by Kruger et al., third molars which were impacted at 19 years showed full eruption by 26 years of age. ${ }^{30}$ Venta et al. showed that similar changes can be seen up to 32 years of age. ${ }^{31}$ Therefore, the impaction status of third molar described in this study is the one recorded in the pretreatment radiograph and may not be the probable final status. Further avenues for research may be to carry out a longitudinal study and assess the changes in third molar status with time. ${ }^{19}$ It is suggested that future epidemiological surveys with larger sample sizes and diverse target populations should be carried out in order to test the validity of findings of our study.

\section{CONCLUSIONS}

1. The majority of erupted mandibular third molars were found in patients with brachyfacial skeletal pattern due to forward direction of mandibular growth contributing to greater resorption at anterior border of ramus and additional space required for third molar eruption.

2. Highest occurrence of completely impacted mandibular third molars was found in patients with dolichofacial skeletal pattern.

3. Among genders, females were found to have higher frequency of mandibular third molar impaction in comparison to males.

4. From the findings of this study, author suggests clinicians to investigate status of mandibular third molar especially in female patients with dolichofacial pattern to prevent any complications associated with impaction of these teeth. As these patients are more prone to complete impaction of mandibular third molar, author recommends performing further research on this at larger scale so that predictions can be well established.

\section{CONFLICT OF INTEREST}

None to declare

\section{REFERENCES}

1. Santosh P. Impacted mandibular third molars: Review of literature and a proposal of a combined clinical and radiological classification. Annals Medi Health Sci Res. 2015;5:229-34.

https://doi.org/10.4103/2141-9248.160177

2. Jain S, Debbarma S, Prasad S. Prevalence of impacted third molars among orthodontic patients in different malocclusions. Indian J Dent Res. 2019;30:238.

https://doi.org/10.4103/ijdr.IJDR_62_17

3. Jakovljevic A, Lazic E, Soldatovic I, Nedeljkovic N, Andric M. 
Radiographic assessment of lower third molar eruption in different anteroposterior skeletal patterns and age-related groups. The Angle Orthodontist. 2015;85:577-84.

https://doi.org/10.2319/062714-463.1

4. Kumar VR, Yadav P, Kahsu E, Girkar F, Chakraborty R. Prevalence and Pattern of Mandibular Third Molar Impaction in Eritrean Population: A Retrospective Study. J Contemp Dent Pract. 2017;18:100. https://doi.org/10.5005/jp-journals-10024-1998

5. Demirel O, Akbulut A. Evaluation of the relationship between gonial angle and impacted mandibular third molar teeth. Anat Sci Int. 2020;95:134-42.

https://doi.org/10.1007/s12565-019-00507-0

6. Sapkota MR, Bhatta S, Shrestha S, Shrestha RM. Position of impacted mandibular third molar in different skeletal facial types. Orthod J Nepal. 2017;7:15-9.

https://doi.org/10.3126/ojn.v7i2.20154

7. Yassaei S, Wlia F, Nik Z. Pattern of third molar impaction; correlation with malocclusion and facial growth. J Oral Health and Dental Management. 2014;13:1096-9.

8. Carter K. The evolution of third molar agenesis and impaction 2016.

9. Juodzbalys G, Daugela P. Mandibular third molar impaction: review of literature and a proposal of a classification. J Oral \& Maxillofac Res. 2013;4.

https://doi.org/10.5037/jomr.2013.4201

10. Bashir S, Rasool G, Afzal F, Hassan N. Incidence of mandibular 3rd molar impactions in different facial types of orthodontic patients seen at Khyber College of Dentistry. Pak Oral Dent J. 2016;36.

11.Broadbent BH. The influence of the third molars on the alignment of the teeth. Am J Orthod Oral Surg. 1943;29: 312-30.

https://doi.org/10.1016/S0096-6347(43)90384-9

12. Legovic M, Legovic I, Brumini G, VanDura I, Cabov T, Ovesnik $\mathrm{M}$, et al. Correlation between the pattern of facial growth and the position of the mandibular third molar. J Oral Maxillofac Surg. 2008;66:1218-24.

https://doi.org/10.1016/j.joms.2007.12.013

13. Abu Alhaija E, AlBhairan H, AlKhateeb S. Mandibular third molar space in different antero-posterior skeletal patterns. The European J Orthod. 2011;33:570-6.

https://doi.org/10.1093/ejo/cjq125

14. Farzanegan F, Goya A. Evaluation of mandibular third molar positions in various vertical skeletal malocclusions. J Dent Mater Tech. 2012;1:58-62.

15. Nanda RS. Agenesis of the third molar in man. Am J Orthodontics. 1954;40:698-706.

https://doi.org/10.1016/0002-9416(54)90058-5
16. Sandhu S, Kaur T. Radiographic evaluation of the status of third molars in the Asian-Indian students. J Oral Maxillofacl Surg. 2005;63:640-5.

https://doi.org/10.1016/j.joms.2004.12.014

17. Obiechina AE, Arotiba JT, Fasola AO. Third molar impaction: evaluation of the symptoms and pattern of impaction of mandibular third molar teeth in Nigerians. Tropical Dent J. 2001:22-5.

18. Grover PS, Lorton L. The incidence of unerupted permanent teeth and related clinical cases. Oral Surg, Oral Medi, Oral Pathol. 1985;59:420-25.

https://doi.org/10.1016/0030-4220(85)90070-2

19. Hattab FN, Ma'amon AR, Fahmy MS. Impaction status of third molars in Jordanian students. Oral Surg, Oral Medi, Oral Pathol, Oral Radiol, Endodont. 1995;79:24-9.

https://doi.org/10.1016/S1079-2104(05)80068-X

20. Schersten E, Lysell L, Rohlin M. Prevalence of impacted third molars in dental students. Swedish Dent J. 1989;13(1-2):7-13.

21. Ma'aita JK. Impacted third molars and associated pathology in Jordanian patients. Saudi Dent J. 2000;12:16-9.

22. Keris EY, Bozkaya S, Öztürk M, Güngör K. Prevalence and characteristics of impacted permanent molars in a Turkish subpopulation. J Oral Maxillofac Radiol. 2016;4:45.

https://doi.org/10.4103/2321-3841.196345

23. de Diego RG, Montero J, López-Valverde N, de Nieves JI, PradosFrutos J-C, López-Valverde A. Epidemiological survey on third molar agenesis and facial pattern among adolescents requiring orthodontic treatment. J clinical and Experimental Dentistry. 2017;9:e1088.

24. Shokri A, Mahmoudzadeh M, Baharvand M, Mortazavi H, Faradmal $\mathrm{J}$, Khajeh S, et al. Position of impacted mandibular third molar in different skeletal facial types: First radiographic evaluation in a group of Iranian patients. Imaging Sci in Dent. 2014;44:61-5. https://doi.org/10.5624/isd.2014.44.1.61

25. Capelli Jr J. Mandibular growth and third molar impaction in extraction cases. The Angle Orthodontist. 1991;61:223-29.

26. Tassoker M, Kok H, Sener S. Is there a possible association between skeletal face types and third molar impaction? A retrospective radiographic study. Medi Principles Pract. 2019;28:70-4. https://doi.org/10.1159/000495005

27. Breik O, Grubor D. The incidence of mandibular third molar impactions in different skeletal face types. Australian Dent J. 2008;53:320-4.

https://doi.org/10.1111/j.1834-7819.2008.00073.x

28. Nanda SK. Patterns of vertical growth in the face. Am J Orthod Dentofac Orthoped. 1988;93:103-16.

https://doi.org/10.1016/0889-5406(88)90287-9

29. Ryalat S, AlRyalat SA, Kassob Z, Hassona Y, Al-Shayyab MH, 
Sawair F. Impaction of lower third molars and their association with age: radiological perspectives. BMC oral health. 2018;18:58. https://doi.org/10.1186/s12903-018-0519-1

30. Kruger E, Thomson WM, Konthasinghe P. Third molar outcomes from age 18 to 26: findings from a population-based New Zealand longitudinal study. Oral Surg, Oral Medi, Oral Pathol, Oral Radiol, and Endod. 2001;92:150-55.

https://doi.org/10.1067/moe.2001.115461

31. Ventä I, Turtola L, Ylipaavalniemi P. Radiographic follow-up of impacted third molars from age 20 to 32 years. International J Oral Maxillofac Surg. 2001;30:54-7.

https://doi.org/10.1054/ijom.2000.0002 